\title{
Sociocultural determinants of home delivery in Ethiopia: a qualitative study
}

\author{
This article was published in the following Dove Press journal: \\ International Journal of Women's Health \\ II April 2016 \\ Number of times this article has been viewed
}

\section{Mirgissa Kaba' \\ Tesfaye Bulto ${ }^{2}$ \\ Zergu Tafesse ${ }^{2}$ \\ Wassie Lingerh ${ }^{2}$ \\ Ismael $\mathrm{Ali}^{2}$}

'Department of Preventive Medicine, School of Public Health, Addis Ababa University, ${ }^{2}$ Integrated Family Health Program, John Snow, Inc., Addis Ababa, Ethiopia
Correspondence: Mirgissa Kaba Department of Preventive Medicine, School of Public Health, Addis Ababa University, PO Box 9086, Addis Ababa, Ethiopia

Email mirgissk@yahoo.com
Background: Maternal health remains a major public health problem in Ethiopia. Despite the government's measures to ensure institutional delivery assisted by skilled attendants, home delivery remains high, estimated at over $80 \%$ of all pregnant women.

Objective: The study aims to identify determinants that sustain home delivery in Ethiopia. Methods: A total of 48 women who delivered their most recent child at home, 56 women who delivered their most recent child in a health facility, 55 husbands of women who delivered within 1 year preceding the study, and 23 opinion leaders in selected districts of Amhara, Oromia, Southern Nations, Nationalities, and Peoples' Region, and Tigray regions were involved in the study. Key informant interview, in-depth interviews, and focus group discussions were conducted to collect data using checklists developed for this purpose. Data reduction and analysis were facilitated by Maxqda qualitative data analysis software version 11.

Results: Findings show that pregnancy and delivery is a normal and natural life event. Research participants unanimously argue that such a life event should not be linked with health problems. Home is considered a natural space for delivery and most women aspire to deliver at home where rituals during labor and after delivery are considered enjoyable. Even those who delivered in health facilities appreciate events in connection to home delivery. Efforts are underway to create home-like environments in health facilities, but health facilities are not yet recognized as a natural place of delivery. The positive tendency to deliver at home is further facilitated by poor service delivery at the facility level. Perceived poor competence of providers and limited availability of supplies and equipment were found to maintain the preference to deliver at home.

Conclusion: The government's endeavor to improve maternal health has generated positive results with more women now attending antenatal care. Yet over $80 \%$ of women deliver at home and this was found to be the preferred option. Thus, the current form of intervention needs to focus on factors that determine decisions to deliver at home and also focus on investing in improving service delivery at health facilities.

Keywords: maternal health service, utilization of maternal health, antenatal care, cultural determinants

\section{Introduction}

Pregnancy and childbirth is a mark of identity and determines a women's status in a family and community. ${ }^{1}$ In addition, pregnancy and childbirth represents life transition that affects the identity of a woman and the relationship between communities and continuity of life. ${ }^{2}$ Such an important life event, however, is associated with suffering, morbidity, and death of the mother and causes family disruption. ${ }^{3-5}$ Early diagnosis, professional follow-up during pregnancy, and skilled assistance during labor and delivery are important measures to lower maternal and newborn mortality and morbidity. ${ }^{5,6}$ Globally, uninterrupted measures have been taken over the years, including the global 
commitment to lower maternal mortality, as reflected in the Millennium Development Goals (MDGs) ${ }^{7,8}$ and the current sustainable development goals. ${ }^{9}$ In connection to the previous MDG, countries were expected to develop their own strategies to reduce maternal mortality in response to set MDG targets. ${ }^{3}$ Such measures contributed to the decline of maternal mortality by 45\% during 1990-2013. Yet, in 2013 alone there were 210 maternal deaths out of 100,000 live births. ${ }^{5}$

With an estimated global maternal mortality ratio (MMR) of 500/100,000 live births, sub-Saharan Africa accounts for $56 \%$ of all maternal deaths across the globe. ${ }^{5,10}$ Relatively high maternal mortality in sub-Saharan Africa is attributed to women's educational status, access to health facilities, cost of services, and home delivery. ${ }^{7,8}$ Conservative estimates show that, from 2011 to 2014, between 130 and 180 million births in South Asia and sub-Saharan Africa took place at home. ${ }^{5}$

Among countries in the sub-Saharan region, Ethiopia maintains one of the highest maternal mortality in the world. ${ }^{5}$ While the World Health Organization estimates maternal mortality in Ethiopia at 350/100,000 live births in 2010, ${ }^{11}$ the Ethiopian Demographic and Health Survey report of 2011 stated that 676 women die for every 100,000 live births. ${ }^{6}$

In order to meet the global commitment of reducing MMR by three-quarters during 1990-2015, the Ethiopian Ministry of Health followed a multipronged approach. . $^{8,12}$ Among others, introduction of the flagship health extension program and training of middle-level health professionals to provide emergency surgery are believed to be important in response to maternal mortality. ${ }^{14}$

Recent mini-Ethiopian Demographic and Health Survey shows that $32 \%$ of women have completed four antenatal care (ANC) visits, $14.5 \%$ pregnant women delivered in health facilities assisted by skilled providers, and $12 \%$ received postnatal care within the first 2 days of delivery. ${ }^{15}$ Such relative improvement, however, is far low compared with most of the sub-Saharan African countries. Recent reports from Malawi and Zimbabwe reveal that of women 15-49 years of age with live birth in the last 2 years, $88 \%$ and $80 \%$, respectively, delivered in the hand of skilled birth attendants at health facilities. Postnatal health care attendance within 2 days after delivery was also reported at $75 \%$ and $73 \%$, respectively, for the two countries. ${ }^{16,17}$ Such evidences reveals that Ethiopia has still a long way to go to improve its maternal health record.

Several studies that were carried out to determine factors associated with maternal health service utilization in general in Ethiopia, and home delivery in particular, identified education and awareness, distance to health facilities, cost of services, and parity as the major determinants of women's choice of place of delivery. ${ }^{18-20}$ On the other hand, few studies revealed that not only individual level factors but also community level factors determine decisions to deliver at home..$^{21-24}$

This manuscript aims to explore sociocultural determinants of home delivery in Ethiopia. The result from this study is believed to generate useful insights not only for programming but also strategies to cater for the established sociocultural factors that sustain women's preference to deliver at home.

\section{Materials and methods Study setting}

Integrated Family Health Program is a program jointly implemented by Pathfinder International and John Snow Inc. in four biggest regions of Ethiopia: Amhara, Oromia, Southern Nations, Nationalities, and Peoples' Region (SNNPR), and Tigray regions. The program, among others, aims to improve maternal, neonatal, and child health with financial support from United States Agency for International Development.

During the study, 21 districts (five each in the three regions and six districts in SNNPR) were benefitting from the Integrated Family Health Program. Since districts within the zone share common socioeconomic and cultural characteristics, one district from the respective regions and five to six kebeles (the smallest formal administrative unit) were chosen for this study.

\section{Study population and participants}

The total population of the study districts was estimated at 650,000 during the year. All women of reproductive age who were regular residents of the selected study kebeles and had a live birth during 12 months preceding the study period were considered as study participants. Study participants were chosen from the health register at the kebele level, and under circumstances where such registers were not available, health extension workers (HEWs) and women development army members at the kebele level were consulted to help identify potential participants based on the selection criterion.

Service users were defined as women who delivered their recent child in a health facility assisted by skilled health personnel, while nonusers were women who delivered their recent child at home. At least two women were randomly chosen from the respective groups in the study kebele. In addition, opinion leaders and husbands, irrespective of where the wife delivered, were identified using the snowball technique and participated in the study. Accordingly, a total of 48 women who delivered their recent child at home, 56 women who delivered at a health facility, 55 husbands, and 23 local leaders who were recognized as knowledgeable about maternal health ('opinion leaders') participated in the study. 


\section{Method of data collection}

Data on personal characteristics such as age, parity, and religion; why women prefer to deliver at a health facility or at home; and determinants of such decision were collected using in-depth interviews from women participants. On the other hand, shared views on pregnancy and delivery, determinants of place of delivery and support provided to women during labor and delivery were collected from opinion leaders, husbands, women development army leaders, and HEWs using either key-informant interviews or focus group discussions.

Data were collected using checklists developed for this purpose. Research assistants who were recruited based on their previous qualitative data collection experience, language command of the study community were trained on objectives of the study, how to use the checklist to ask questions, probe, and record. Two data collectors were assigned to the respective regions to generate data. They interviewed research participants and recorded responses using recorder in addition to on-spot scribbles.

\section{Method of data analysis}

Data so generated from different sources were transcribed and field notes were expanded while in the field. Transcripts and notes were read and re-read by the Pathfinder International and two research assistants to develop themes and subthemes in reference to the objectives of the study and identify conflicting opinions. Accordingly, findings on determinants of place of delivery were categorized under three themes: individual, cultural, and health facility level factors. Under each theme, subthemes were defined as detailed in Table 1, and verbatim quotes that represented collective opinions were applied to substantiate results. Quotes were translated to English from local languages (Tigrigna in Tigray, Afaan Oromo in Oromia, and Amharic in SNNPR and Amhara) for use in this study.

Findings categorized under such themes and subthemes were thus analyzed, interpreted, and presented. The

Table I Categories of themes and subthemes

\begin{tabular}{ll}
\hline Theme & Subthemes \\
\hline Individual factor & - Awareness \\
& - Fear of exposure to wind \\
- Pain of leaving children and livestock behind \\
Cultural factor & - Pregnancy and delivery is normal \\
& - Home delivery is natural \\
& - Housewarming facilitates delivery \\
& - Death is unavoidable \\
Facility factors & - Hearsays on death of a woman in a health facility \\
& - Unwelcoming providers \\
& - Limitation of provider's competence \\
& - Limited or no supplies and equipment
\end{tabular}

analysis was facilitated by the use of Maxqda qualitative data analysis software version 11 . Verbatim quotes that represent wider views were considered to substantiate findings under each category.

\section{Ethical consideration}

In order to ensure appropriate ethical review based on regional contexts, the study team submitted the study protocol to the Amhara, Oromia, SNNPR, and Tigray Regional Health Bureaus and obtained ethical clearance to conduct the study. During data collection, research participants were provided with an explanation on the purpose of the study and how the results would contribute to improving maternal health service provision. Furthermore, participants were assured of confidentiality of information. Participants willing to partake in this study then provided informed written consent. In this manuscript, personal identifiers were omitted to maintain confidentiality, while age and type of data collection were mentioned in direct quotes.

\section{Results \\ Demographic characteristics of study participants}

An equal proportion of six out of ten women service users and nonservice users were found to be $<30$ years of age, while husbands were found to be on average 7 years older than women. Opinion leaders on the other hand were $>40$ years of age. Educational characteristics of participants show that the majority of both service users and nonusers (more than six out of ten) were found to have no formal education. While two-thirds of nonusers and seven out of ten users were found to have one to three children, nearly one out of five users and nonusers were found to have four to five children. Over threequarter of participants in Amhara and Tigray were followers of Orthodox Christians, two out of three in SNNPR, and similar proportion in Oromia were found to be Protestants and Muslims, respectively (Table 2). All women participants irrespective of place of delivery were housewives but were found to be active in the family's farm activity.

\section{Individual level determinants}

Awareness about maternal health services has improved

Findings showed that claims of awareness about maternal health, particularly ANC and institutional delivery are widespread. One of the participants stated:

[...] after Health Extension Workers (HEWs) started operating in this community, awareness about pregnancy and delivery has improved. [nonuser, SNNPR] 
Table 2 Sociodemographic characteristics of women participants by region

\begin{tabular}{|c|c|c|c|c|c|}
\hline Characteristics & Amhara & Oromia & SNNPR & Tigray & Percentage \\
\hline \multicolumn{6}{|l|}{ Users: age } \\
\hline$<20$ years & 0 & 0 & 1 & 1 & 0.04 \\
\hline $20-24$ years & 4 & 5 & 4 & 5 & 0.32 \\
\hline $25-29$ years & 5 & 3 & 5 & 4 & 0.30 \\
\hline 30-34 years & 2 & 3 & 2 & 2 & 0.16 \\
\hline $35-39$ years & I & 4 & 1 & 2 & 0.14 \\
\hline$\geq 40$ years & I & 0 & 0 & I & 0.04 \\
\hline Total & 13 & 15 & 13 & 15 & 1.00 \\
\hline \multicolumn{6}{|l|}{ Nonusers: age } \\
\hline$<20$ years & 0 & I & 0 & 0 & 0.02 \\
\hline 20-24 years & 2 & 2 & 2 & 4 & 0.21 \\
\hline $25-29$ years & 4 & 3 & 5 & 6 & 0.38 \\
\hline 30-34 years & 3 & 3 & 3 & 2 & 0.23 \\
\hline $35-39$ years & 2 & I & 2 & 2 & 0.15 \\
\hline$\geq 40$ years & I & 0 & 0 & 0 & 0.02 \\
\hline Total & 12 & 10 & 12 & 14 & 1.00 \\
\hline \multicolumn{6}{|l|}{ Users: education } \\
\hline No formal education & 8 & 10 & 7 & 9 & 0.61 \\
\hline Primary education & 4 & 4 & 4 & 4 & 0.29 \\
\hline Secondary education & I & I & 2 & 2 & 0.11 \\
\hline Total & 13 & 15 & 13 & 15 & 1.00 \\
\hline \multicolumn{6}{|l|}{ Nonusers: education } \\
\hline No formal education & 8 & 6 & 8 & 8 & 0.63 \\
\hline Primary education & 2 & 3 & 3 & 5 & 0.27 \\
\hline Secondary education & 2 & I & I & I & 0.10 \\
\hline Total & 12 & 10 & 12 & 14 & 1.00 \\
\hline \multicolumn{6}{|l|}{ Users: children ${ }^{\mathrm{a}}$} \\
\hline Only one & 3 & 4 & 2 & 4 & 0.23 \\
\hline $2-3$ & 6 & 7 & 5 & 8 & 0.46 \\
\hline $4-5$ & 3 & 3 & 4 & 3 & 0.23 \\
\hline$>5$ & I & 1 & 2 & 0 & 0.07 \\
\hline Total & 13 & 15 & 13 & 15 & 1.00 \\
\hline \multicolumn{6}{|l|}{ Nonusers: children ${ }^{a}$} \\
\hline Only one & 2 & I & 3 & 3 & 0.19 \\
\hline $2-3$ & 6 & 5 & 3 & 6 & 0.42 \\
\hline $4-5$ & 2 & 3 & 4 & 4 & 0.27 \\
\hline$>5$ & 2 & I & 2 & I & 0.12 \\
\hline Total & 12 & 10 & 12 & 14 & 1.00 \\
\hline \multicolumn{6}{|l|}{ Users: religion } \\
\hline Orthodox & 9 & 5 & 4 & 13 & 0.55 \\
\hline Muslim & 3 & 6 & 3 & I & 0.23 \\
\hline Protestant & I & 2 & 6 & I & 0.18 \\
\hline Other & 0 & 2 & 0 & 0 & 0.04 \\
\hline Total & 13 & 15 & 13 & 15 & 1.00 \\
\hline \multicolumn{6}{|l|}{ Nonusers: religion } \\
\hline Orthodox & 10 & 4 & 3 & 12 & 0.60 \\
\hline Muslim & 2 & 6 & 3 & 2 & 0.27 \\
\hline Protestant & 0 & 0 & 6 & 0 & 0.13 \\
\hline Total & 12 & 10 & 12 & 14 & 1.00 \\
\hline
\end{tabular}

Notes: Service users were defined as women who delivered their most recent child in a health facility assisted by skilled health personnel, while nonusers were defined as women who delivered their most recent child at home. ${ }^{\text {aNumber }}$ of children born to a woman.

Abbreviation: SNNPR, Southern Nations, Nationalities, and Peoples' Region.

HEWs, the one to five networkers, health development army, and kebele leaders were found to be the sources of information. It was consistently argued that

HEWs teach women as well as the public at large about the need to attend an ANC during pregnancy and deliver in a health facility. [user, Amhara]
Although awareness was found to be widespread, it was evident that further probing showed what is known about ANC and associates services, as well as institutional delivery is limited. Participants could not mention what constituted ANC and institutional delivery related services. 


\section{Concerns about children and livestock back at home}

It was found that those who delivered at a health facility were often concerned about their children and livestock they left behind.

During this last delivery, my husband accompanied me to the health center and there was no one to look after my children and livestock. I was quite worried about what could happen to them. So, delivering at a health facility is not the best option, at least to me, since I do not have someone to care for my children and livestock in my absence. [user, Oromia]

This is further complicated when providers advise you to stay around the facility.

There are times when pregnant women in term are advised to stay around a health facility for closer follow up. Imagine husband and family members [having to] travel between a health facility and home. This makes me feel unease. [user, Amhara]

Opinion leaders and husbands also expressed concern over keeping women at a health facility before delivery.

Although I give priority to the life of my wife, keeping her at a facility longer before delivery is very difficult in our situation. Without women the house is lifeless and difficult for children. [husband, SNNPR]

\section{Avoid exposure to wind and sun}

It was found that both users and nonusers believed that exposure to wind compromises the health of a woman and newborn. Almost all participants argued that women should stay indoors and at home during labor and after delivery. A participant explained that:

I would have liked to deliver at home because I am protected against exposure to wind. Normally a women's body is open and sensitive to wind after delivery. So, she should stay indoors. I was sick for few months after delivery since I was exposed to wind on my way back from the health center. [user, Tigray]

Staying at home after delivery is unanimously believed to keep women and newborn safe. Inasmuch as ambulance escort to a health facility was appreciated, it was argued that

After delivery nobody cared about me. I could not get transport and did not have a relative to stay with. My husband brought a horse to pick me up. I was sick for three weeks because I was exposed to wind and cold. [user, Oromia]

\section{Cultural determinants}

Pregnancy and delivery are normal life events

All participants invariably argue that pregnancy and childbirth is normal. On the other hand, a visit to a health facility is always believed to be associated with health problems. At least two in three women participants in both groups of users and nonusers felt that it is luxurious to visit health facility if there is no problem during pregnancy and labor. Participants invariably pointed out that "loss of appetite, nausea, vomiting, discomfort and tiredness are normal features in connection to pregnancy and are not illnesses that needs to be treated". One of the nonusers pointed out that

Pregnancy and childbirth is a natural life process and is not an illnesses. So, I do not see why I should visit a health facility during pregnancy. [nonuser, Amhara]

One of the participants from Tigray also stated that

While pregnancy and childbirth is a normal process, heath extension workers and our kebele leaders force us to go to a health facility. Why should I visit a health facility while I am healthy. [nonuser, Tigray]

Opinion leaders were found to have the same opinion that pregnancy and delivery is not a problem that deserves medical attention under all circumstances.

Visit to health facility by a woman is not reasonable when it is only for mere checkup or to deliver there. [opinion leader, SNNPR]

A 20-year-old mother living approximately $200 \mathrm{~m}$ away from the health center pointed out:

Delivery in a health facility is an option when labor is taking longer and painful. Thank be to Allah I delivered my first son at home assisted by my mother without any problems. [nonuser, SNNPR]

\section{Rituals at home make childbirth easier}

Home delivery is considered normal by participants.

I have three children and all were born at home without any noise. [nonuser, SNNPR]

Housewarming during labor and delivery was found to be an important event.

I delivered my last born in a health center because I was told that I would risk my life if I stayed at home. I missed the comfortable and warmer home with close relatives and neighbors around me. I delivered my previous one at home and it was more comfortable. [user, Tigray] 
A woman from Oromia pointed out that:

The moment labor started neighbors came and put a fire on. The warmth was relaxing and I feel this made delivery easier. [nonuser, Oromia]

Furthermore, the cheering and supportive mood at home during labor with experienced women around was argued to be helpful. Women users were found to have mixed feelings. Although institutional delivery is considered useful, there are several socially sanctioned rituals that may be missed by delivering at facility.

You know, when you deliver at a health facility, other than the warmth of the house, you miss rituals such as the sudden eruption of ululation right upon delivery which heralds the news of birth. [user, Tigray]

She further noted that the "[...] number of ululation ushers whether the newborn is a son or a daughter". Right after delivery, it was found that preparation of porridge, which has its own ritual, follows. Women nonusers were found to share similar feeling.

No matter how poor you may be ululation upon delivery and preparation of porridge and eating together is normal. Every pregnant woman prepares all materials for porridge before expected due date. [nonuser, Oromia]

Husbands and opinion leaders argued that delivery at home and events that follow are established rituals.

For us [men], in those good old days, the moment the news of birth broke, you rushed to grab your rifle and go out to the fire, you may also have slaughtered sheep or oxen depending on the level of your wealth and sex of the newborn. Although this is not the case to date, the feeling of joy is there and you could share what you have with friends and relatives when it happened at home. [opinion leader, Amhara]

Participants were found to recognize government's endeavor to make health facilities friendly to encourage women to deliver in health facilities assisted by skilled attendants. A woman commented that:

Such an event in a health facility is not as captivating and interesting as it is at home. [user, Oromia]

Although participants recognize current measures by government to encourage every woman to deliver in a health facility, there is concern over the level of intrusion and obligatory measures. A participant commented that:

If the purpose of visiting a health facility during pregnancy and delivering in a health facility is for me, why should local formal leaders, police, school teachers etc be concerned so much? [user, SNNPR]

If women get sick in the process of delivery, no one waits to see her dying - we rush her to health facility. Today however, if a husband doesn't send his wife to a health facility, he may be sent to prison. We do not understand why such a measure is taken. [opinion leader, Amhara]

Supporting delivery process at home is considered to be the responsibility of neighbors, friends, and family members. At home, women in labor are supported and cheered up by neighbors and relatives. In addition to housewarming activities, women pray to St Mary to ease the labor, chant, and encourage delivering women to push. These are locally recognized set of support to women in labor.

When you are in labor and shout in pain, experienced women hang around and pretend as if they are also in labor and encourage the woman in labor to push. So, you are not alone in pain while delivering at home. [nonuser, Oromia]

Delivering at facility, however, lacks such a luxury. A woman noted that,

I was taken to a health center since my labor took longer.

Everyone who had accompanied me was chased out; the room was empty and cold. It was embarrassing to be alone in pain. [user, Amhara]

\section{I do not see why women should deliver at a health facility if death can't be avoided}

Information on previous unwelcoming experiences of a woman who delivered in a health facility was found to influence the decision to deliver in a health facility.

As I told you, I delivered three children in the health facility and the last one died there. I also heard there are women who died at a health facility during delivery. I do not see why women should deliver at a health facility if death cannot be avoided. [user, SNNPR]

All participants were found to maintain a very general belief that "if the Almighty decides, no one could avert death". An opinion leader stated that:

A woman may die while laboring be it at a health facility or at home if that is her destiny. [husband, SNNPR] 


\section{Facility level determinants}

It was not possible to call and get [an ambulance] as quickly as we wanted

Health centers are relatively closer, although it is not as easy to get to a health facility:

If a health center was close to our village, we would have better access. However, the health center is not close, nor do we have a transport facility. [husband, Tigray]

Ambulances were found operational in all study setting. Nonetheless, getting ambulance service is not easy.

At the onset of labor we start calling for an ambulance. It was not possible to get the ambulance as quickly as we wanted. Poor telephone connection is the major problem. Other times, I heard that the ambulance was engaged in other activities and was not available in time. [opinion leader, Tigray]

Failure to get ambulance service in time determines where to deliver.

Upon commencement of labor, I called for the ambulance but the driver did not pick his phone. There was no other alternative, she delivered at home and delivery was smooth. [nonuser, Oromia]

The problem associated with ambulance is also about getting escort back home. It was consistently argued that discharge following delivery is fast and this gives women a lot of discomfort especially when there is no transportation service to get them back home.

Discharged 'early' we find it difficult to get back to home without getting my wife and the newborn exposed to wind. Since there was no transport service, I took my wife home on horseback, although this was not comfortable. [husband, Tigray]

\section{HEW did not know when delivery would occur}

Two out of three women who attended ANC but eventually delivered at home unanimously argued that home delivery was not their choice. It was attributed to "the sudden onset of labor". One of the participants pointed out that:

Labor occurred suddenly and was intense, making it difficult to go to health facility. However, delivery was quite smooth. [nonuser, Oromia]
Women participants commonly argued that HEWs do not know the date of delivery:

I was misled by the health extension worker who told me I would deliver after 15 days, but I delivered on the 7th day. [user, SNNPR]

Even health workers at a facility level were blamed for failure to know what the due date should be. A woman visited a health center with pain and was sent back home and had to deliver at home.

I went to a health center because I had a feeling that I would deliver that very day. However, the nurse checked me and she advised me to return back after five days. I had to return back home and delivered my baby without any problem that evening. [nonuser, Oromia]

\section{Providers do not even know what a laboring woman goes through}

Women users unanimously argued that service providers at facility levels are not friendly in their approach. All participants argued that providers are not humane in their approach. Most of those who delivered in a health facility argued that providers lack sympathy for a woman in labor.

Some of the health service providers are arrogant and do not even know what a laboring woman goes through. At home I am cared for and people are around me with supporting hands, while at a health facility providers do not care about my pain. [user, Tigray]

A husband from SNNPR pointed out that:

My wife was admitted to a health center. Then she was not attended to. She was in pain and I went out to call the nurse who was with her friends chatting. She did not pay much attention to my plea. After awhile one of the nurses came over and yelled at my wife, which was an additional pain. [husband, SNNPR]

Mistreatment of women in labor at a health facility is a common phenomenon.

A provider at the facility treated me like a child. She came over and shouted at me saying 'shut up', 'do not open your mouth' etc which was humiliating to me. I do not think this is acceptable. I was afraid whether I could take it anymore. [user, Oromia]

Furthermore, despite recognition of the value of institutional delivery, almost all those who delivered in a health 
facility have invariably expressed disinterest about the service they obtained. It was commonly expressed that:

These young girls do not understand the pain they give to laboring women by the way they deal with us. [user, Amhara]

\section{There are not enough delivery beds [couches] and rooms in a health facility}

Findings show that lack of water, electric power, as well as delivery couch in facility are major factors affecting decisions to deliver at a health facility. A woman user argued that

I do not think health facilities have the necessary materials and equipment. I was taken to the health center around midnight. The nurse helped me deliver while my husband held a torch for him. [user, Wolaita]

Another woman pointed out that

There are not enough delivery beds [couches] and rooms in the health center. Not long after I delivered, another woman in labor was brought in by ambulance. They took me out of that room and put me in a small room on the floor. [user, Oromia]

\section{Discussion}

Evidence shows that maternal health problems are critical public health concerns across the world and are more pronounced in sub-Saharan Africa. Every year unacceptably large numbers of mothers die due to complications that could be managed with defined procedures during pregnancy, delivery, and postpartum. ${ }^{3,5}$ In 2013 alone, 210/100,000 live births died in connection to pregnancy and delivery and over $99 \%$ were from resource-poor settings. ${ }^{5}$ Although it is difficulty to accurately measure material mortality, available evidence shows variation of estimates. While the World Health Organization estimated MMR in Ethiopia at 350/100,000 live births for 2010/11, ${ }^{11}$ the National Demographic and Health Survey estimated MMR for the same period at 676/100,000 live births. ${ }^{6}$ In either case, however, maternal mortality in Ethiopia remains one of the highest in the world. ${ }^{5}$

The health sector has taken concrete measures including improved access to services at the community level and strengthening the health systems to improve maternal health service utilization. Arguably, the government has taken additional measures such as availing ambulance services to escort women in labor to health facilities, training health care providers, improving demands for services at community level, and making delivery at a health facility as home like as possible. ${ }^{14}$ Yet, in Ethiopia, over $85 \%$ of women deliver at home without assistance by skilled providers, running the risk of morbidity and mortality. Studies have attributed home delivery to education, access to health facilities, long waiting time for service, place of residence, poor quality of services, and husband's disapproval. ${ }^{18-20}$ Recent analysis of demographic and health data from Ethiopia reveal that not only individual factors but also community level factors determine the decision to deliver at home. ${ }^{25}$ This study helped to disaggregate reasons for home delivery at individual, cultural, and facility level factors.

At the individual level, several factors were found to determine decisions over place of delivery: limited awareness, fear of exposure to sun and wind right after delivery, and concern over leaving children and livestock at home were found to influence choice of place of delivery. These were further consolidated by established belief that home is a natural place for delivery, with such rituals as house warming, ululation, porridge preparation, and support by neighbors and family members during labor. Various studies have documented that home delivery is adored. ${ }^{21-24,26}$ These studies argue that neither do women feel institutional delivery as necessary and desirable nor customary. Family members, neighbors, and traditional birth attendants were considered as socially and culturally closer, understanding the interest of women in labor than the health care providers who are younger and inexperienced. ${ }^{22,23}$ Most of these factors have a sociocultural basis and are widely documented. ${ }^{22-24,26,27}$

The government's measures to improve maternal health service delivery are encouraging, particularly the recent steps of availing ambulances to escort laboring women to health facilities improves access. However, failure to transport women back home after delivery is a source of anguish for women and the community at large, due to established fear of exposure to wind and sun. Furthermore, erratic telephone connection and ambulance drivers' failure to answer phone whilst on call are emerging concerns. Communication skill of providers was found to be limited in all the study areas, limiting comfort of women in labor and her family. The fact that providers are young and inexperienced made it difficult to meet expectation of a woman in labor. Women in labor want to be well received at health facilities, respected, treated with kindness, dignity, and not shouted at. This is documented in a study from Malawi ${ }^{28}$ and is believed to be the universal expectation of a woman in labor, along with meeting the basic tenets of human rights. Coupled with limitation in availability of supplies, lack of electric power, 
delivering coach, health facilities are not yet friendly to pregnant women's expectations. ${ }^{3,6,29}$

In addition, previous experiences and/or hearsays about problems encountered in a health facility in the course of delivery resonates widespread fear and casts doubt on considering health facility for delivery.

\section{Conclusion and recommendation}

This study has generated important sociocultural evidences of why women tend to deliver at home. Findings show that there are comprehensive factors that operate in tandem to affect decisions on place of delivery. The study underscored that reasons for home delivery are anchored in individual, community, and health facility level factors. Although endeavors are underway at different levels to improve institutional delivery, more attractions are there to maintain home delivery. While comprehensive countrywide sociocultural mapping of how maternal health is perceived and how to improve maternal health service utilization is required, some of the findings from this study may help government, civil society organizations, and private organizations to design comprehensive and integrated interventions to improve friendliness of health facilities, including empowerment of providers with communication skills and provision of transportation services on the way back home after delivery, in addition to measures at individual and sociocultural levels.

\section{Acknowledgments}

The authors would like to thank Amhara, Oromia, SNNPR, and Tigray Regional Health Bureaus for their ethical clearance. Research assistants and participants are duly acknowledged for their contribution to the study, both in generating evidences and providing genuine information, respectively. Finally, the authors would like to thank the Integrated Family Health Program for the financial support they provided for this study.

\section{Disclosure}

The authors report no conflicts of interest in this work.

\section{References}

1. Lynn C, Socia S, Joyce C. Cultural and spiritual meanings of child birth. J Holist Nurs. 1999;17(3):280-295.

2. Mariotti P, editor. The Maternal Lineage: Identification, Desire, and Trans-generational Issues. East Sussex: Routledge, 2012. Available from: http://www.psypress.com/the-maternal-lineage-9780415681643

3. Hogan MC, Foreman KJ, Naghavi M, et al. Maternal mortality for 181 countries, 1980-2008: a systematic analysis of progress towards Millennium Development Goal 5. Lancet. 2010;375:1609-1623.
4. Yamin AE, Boulanger VM, Falb KL, Shuma J, Leaning J. Costs of inaction on maternal mortality: qualitative evidence of the impacts of maternal deaths on living children in Tanzania. PLoS One. 2013;8(8): e71674. doi:10.1371/journal.pone.0071674.

5. WHO, UNICEF, UNFPA, The World Bank and the United Nations Population Division. Trends in Maternal Mortality: 1999-2013. Geneva, 2014.

6. CSA (Central Statistical Agency) and ICF International. 2012. The Ethiopian Demographic and Health Survey 2011. Addis Ababa and Calverton, Maryland.

7. Stephenson R, Baschieri A, Clements S, Hennink M, Madise N. Contextual influences on the use of health facilities for childbirth in Africa. Am J Pub Health. 2006;96(1):84-93.

8. Crowe S, Utley M, Costello A, Page C. How many births in sub-Saharan Africa and South Asia will not be attended by a skilled birth attendant between 2011 and 2015? BMC. 2012;12:4. doi:10.1186/1471-2393-12-4.

9. ICSU and ISSC. Review of the Sustainable Development Goals: The Science Perspective. Paris: International Council for Science; 2015.

10. UNFPA. Trends in Maternal Health in Ethiopia: Challenges in Achieving the MDG for maternal mortality. In-depth Analysis of the EDHS 2000-2011; December 2012.

11. World Health Organization, author. World Health Statistics 2013. Available from: www.who.int/entity/gho/.../world_health_statistics/ EN_WHS2013_Full.pdf

12. Ghebreyesus AT. Achieving the health MDGs: country ownership in four steps. Lancet. 2010;376(9747):1127-1128. Available from: http:// www.lancet.com/journals/lancet/article/PIIS0140-6736(10)61465-1/ fulltext?_eventId=login

13. Karim AM, Admassu K, Schellenberg J, et al. Effect of Ethiopia's Health Extension Program on maternal and newborn health care practices in 101 rural districts: a dose-response study. PLoS One. 2013;8(6):e65160. doi:10.1371/journal.pone.0065160.

14. FMoH and United Nations. MDG Acceleration Compact: Accelerated Action Plan for Reducing Maternal Mortality. Addis Ababa Ethiopia; 2014.

15. CSA. Ethiopia Mini Demographic and Health Survey, 2014. Addis Ababa Ethiopia.

16. Zimbabwe National Statistical Agency. Multiple Indicator Cluster Survey: Key Findings, 2014, Harare, Zimbabwe; 2014.

17. Malawi National Statistical Office. Malawi MDG End line Survey: Key findings, 2014. Zomba, Malawi; 2014.

18. Warren C. Care seeking for maternal health: challenges remain for poor women. Ethiop J Health Dev. 2010;24 Special Issue 1:100-104.

19. Worku AG, Yalew AW, Afework MF. Factors affecting utilization of skilled maternal care in Northwest Ethiopia: a multilevel analysis. BMC Int Health Human Rights. 2013;13:20.

20. Birmeta K, Dibaba Y, Woldeyohannes D. Determinants of maternal health care utilization in Holeta town, Central Ethiopia. BMC Health Ser Res. 2013;13:256.

21. Chanza D, Chirwa E, Maluwa A, Malata A, Masache G. Factors affecting the choice for home deliveries in Malawi. Afr J Midwifery Women's Health. 2012;6:125-130.

22. Bedford J, Gandhi M, Admassu M, Girma A. 'A normal delivery takes place at home': a qualitative study of the location of childbirth in rural Ethiopia. Matern Child Health J. 2012;17(2):230-239. doi:10.1007/ s10995-012-0965-3.

23. Shiferaw S, Spigt M, Godefrooij M, Melkamu Y, Tekie M. Why do women prefer home births in Ethiopia? BMC Pregnancy Childbirth. 2013;13:5. Available from: http://www.biomedcentral.com/1471$2393 / 13 / 5$

24. Yeboyo H, Aemayehu M, Kahsay A. Why do women deliver at home? Multilevel modeling of Ethiopian demographic and health survey data. PLoS One. 2015;10(4):e0124718. doi:10.1371/journal. pone. 0124718 .

25. Tarekegn SM, Lieberman LS, Giedraitis V. Determinants of maternal health service utilization in Ethiopia: analysis of the 2011 Ethiopian Demographic and Health Survey. BMC Pregnancy Childbirth. 2014;14:161. Available from: http://www.biomedcentral.com/1471-2393/14/161 
26. Ogolla JO. Factors associated with home delivery in west Pokot country of Kenya. Adv Public Health. 2015;Article ID 493184:6 pages. Available from: http://dx.doi.org/10.1155/2015/493184

27. Cheptum J, Gitonga M, Mutua E, Mukui S, Ndambuki J, Koima W. Barriers to access and utilization of maternal and infant health services in Migori, Kenya. Developing Country Stud. 2014;4(15):48-52.
28. Ewa EE, Lasisi CJ, Maduka SO, Ita AE, Ibor UW, Anjorin OA. Perceived factors influencing the choice of antenatal care and delivery centers among childbearing women in Ibadan North South-Western Nigeria. EJESM. 2012;5(4):373-383.

29. Moyer CA, Mustafa A. Drivers and deterrents of facility delivery in subSaharan Africa: a systematic review. Reprod Health. 2013;10:40.

International Journal of Women's Health

Dovepress

\section{Publish your work in this journal}

The International Journal of Women's Health is an international, peerreviewed open-access journal publishing original research, reports, editorials, reviews and commentaries on all aspects of women's healthcare including gynecology, obstetrics, and breast cancer. The manuscript management system is completely online and includes

a very quick and fair peer-review system, which is all easy to use. Visit http://www.dovepress.com/testimonials.php to read real quotes from published authors.

\footnotetext{
Submit your manuscript here: http://www.dovepress.com/international-journal-of-womens-health-journal
} 